\title{
ADAM17 overexpression is associated with poorer clinical outcomes in cancer patients: a systematic review and meta- analysis
}

\author{
XuFeng Peng ${ }^{1, *}$, Bo Hao ${ }^{3, *}$, Nailong $\mathrm{Cao}^{1}$, Jihong Wang ${ }^{1}$, Xiangguo $\mathrm{Lv}^{2}$ and XinRu \\ Zhang ${ }^{1}$ \\ ${ }^{1}$ Department of Urology, Shanghai Jiao Tong University Affiliated Sixth People's Hospital, Shanghai 200233, China \\ ${ }^{2}$ Department of Urology and Andrology, Shanghai Renji Hospital, Shanghai Jiao Tong University, School of Medicine, Shanghai \\ 200001, China \\ ${ }^{3}$ Department of Cardiothoracic Surgery, The Third Affiliated Hospital of Soochow University, Changzhou 213003, China \\ *These authors have contributed equally to this work \\ Correspondence to: XinRu Zhang, email: 15800558925@163.com \\ Xiangguo Lv, email: chnlvsc@163.com \\ Keywords: ADAM 17; cancer; prognosis; lymph node metastasis; distant metastasis \\ Received: July 15, $2017 \quad$ Accepted: December 26, $2017 \quad$ Published: January 02, 2018 \\ Copyright: Peng et al. This is an open-access article distributed under the terms of the Creative Commons Attribution License 3.0 \\ (CC BY 3.0), which permits unrestricted use, distribution, and reproduction in any medium, provided the original author and source \\ are credited.
}

\section{ABSTRACT}

\begin{abstract}
ADAM17 (a disintegrin and metalloproteinase 17) is overexpressed in many types of cancer, and its high expression in cancer patients is associated with increased risk of metastasis and a poorer prognosis. However, the clinical value of ADAM17 as a tumor biomarker remains largely unknown. In this meta-analysis, we investigated the relationships between ADAM17 levels, cancer metastasis, and patient prognosis. Twelve eligible studies involving a total of 1816 patients were identified in searches of the PubMed, Embase, Cochrane, and Chinese National Knowledge Infrastructure databases. Analysis of these studies revealed that ADAM17 overexpression is positively associated with lymph node metastasis in a fixed effect model and distant metastasis in a random effect model. Moreover, high ADAM17 expression was predictive of shorter overall and progression-free survivalof cancer patients in fixed effect models. These results suggest that ADAM17 maybe a useful biomarker for predicting metastasis and prognosis in cancer patients and may also aid in risk stratification and selection of individualized treatments.
\end{abstract}

\section{INTRODUCTION}

Cancer has become one of the most important diseases threatening human health and life [1]. Despite increasing knowledge of the complex mechanisms behind neoplastic disease, only a few biomarkers are routinely used to diagnose some cancers in the clinical setting (e.g., PSA [2] and AFP [3] in prostate and hepatic cancer, respectively). Most patients have either regional or distant metastatic disease, which requires more complicated therapies and is associated with poor prognosis, upon diagnosis [4]. It is therefore important to identify additional biomarkers that can predict prognosis and guide individualized treatments.
ADAMs (a disintegrin and metalloproteinases), originally also known as MDC (metalloproteinase/ disintegrin/cysteine-rich) proteins, are multi-domain membrane-anchored proteins belonging to the Metzincins superfamily of metalloproteases [5]. More than 30 ADAMs have been identified in various animal species, and some are implicated in several pathophysiological conditions [6]. ADAM17 (also known as tumor necrosis factor-alpha-converting enzyme, TACE), which cleaves the pro-inflammatory cytokine TNF-alpha from its membrane-bound precursor, is the best-characterized ADAM [7]. ADAM17 plays an important role in malignant lesionsby regulating the epidermal growth factor receptor 
(EGFR)/phosphoinositide 3-kinase/protein kinase B (AKT) pathway [8]. Elevated ADAM17 expression is associated with poor prognosis in a number of human cancers, such as clear cell renal cell carcinoma, non-small cell lung cancer, esophageal squamous cell carcinoma, and gastric cancer [9]. ADAM17 may act as both a novel prognostic biomarker and a potential therapeutic target. However, the prognostic value of ADAM17 has not been well-characterized. We therefore conducted a systemic review and meta-analysis to examine the prognostic value of ADAM17 with regard to tumor metastasis, progression, and survival.

\section{RESULTS}

\section{Search results}

A flow diagram of the study selection process is shown in Figure 1. A total of 276 primary research articles were identified in database searches. After removal of duplicates (176 records), the 100 remaining articles were screened for eligibility. Of these, 85 were excluded based on title, abstract, publication type, or full text, leaving 15 articles for further evaluation. Three additional articles did not meet the inclusion criteria (2 lacked crucial data, including $\mathrm{HR}$ and 95\% $\mathrm{CI}$; 1 used two cutoffs) and were therefore excluded. As a result, a total of 12 studies involving 1816 cases were ultimately included in this meta-analysis.

\section{Characteristics of included studies}

Basic information for the included studies is shown in Table 1. The 12 included articles were published between 2005 and 2015. Ten different tumor types were evaluated in this meta-analysis; 3 studies examined gastric cancer [11-13], and 1 study each examined clear cell renal cell carcinoma (cRCC) [10], non-small cell lung cancer (NSCLC) [9], esophageal squamous cell carcinoma (ESCC) [14], gallbladder carcinoma [15], uterine cervical carcinoma [16], breast cancer [17], extrahepatic cholangiocarcinoma (ECC) [18], glioma [19], and ovarian cancer [20]. Cutoff values differed among the included studies. Additionally, univariate analysis was used in three studies, while multivariate analysis was used in the remaining nine. OS was examined in ten studies and PFS was evaluated in five. Of the six studies that examined the relationship between ADAM17 expression and lymph node metastasis, positive correlations were identified in three. Original OS (HRs and 95\% CIs) and PFS data from the included studies are shown in the forest plots in Figures 2 and 3; original lymph node and distant metastasis data are summarized in Table 2.

\section{Quality assessment}

The quality of the 12 studies included in our metaanalysis was evaluated according to the Newcastle-Ottawa scale. Quality scores ranged from 6 to 8, with a mean of 7; higher scores indicate better methodology. None of the studies were excluded from subsequent analyses based on these scores.

\section{ADAM17 expression is associated with lymph node metastasis}

Six articles examined ADAM17 overexpressionin cancer tissues from patients with and without lymph

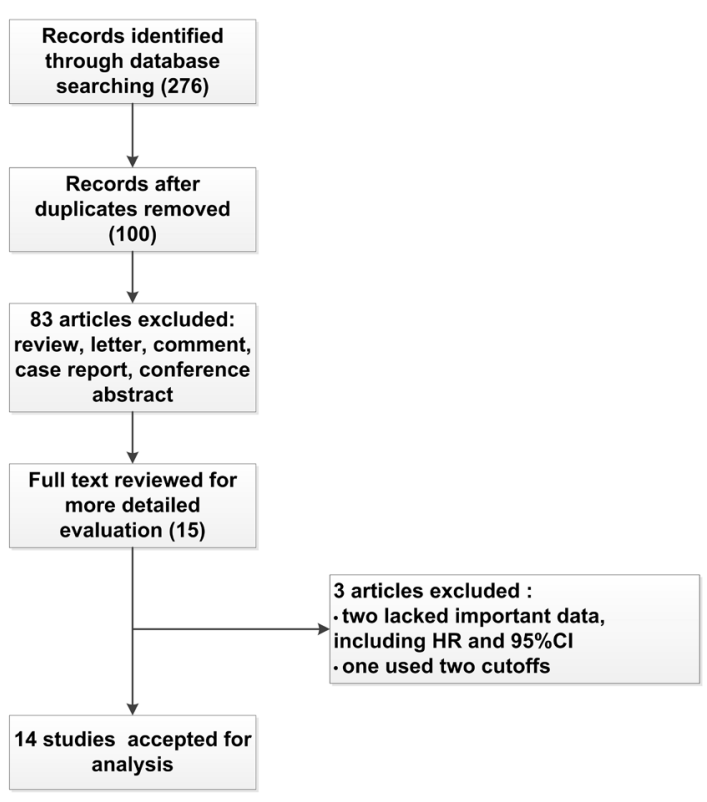

Figure 1: Flow diagram of the study selection process. 
Table 1: Characteristics of the included studies

\begin{tabular}{|c|c|c|c|c|c|c|c|c|c|c|}
\hline First author & Year & Country & $\begin{array}{l}\text { Tumor } \\
\text { type }\end{array}$ & $\begin{array}{c}\text { Case } \\
\text { number }\end{array}$ & $\begin{array}{l}\text { Survival } \\
\text { analysis }\end{array}$ & $\begin{array}{c}\text { Multivariate } \\
\text { analysis }\end{array}$ & $\begin{array}{l}\text { Follow-up } \\
\text { (month) }\end{array}$ & Cut-off value & HR & Treatment \\
\hline $\begin{array}{l}\text { Guorong Li } \\
{[10]}\end{array}$ & 2014 & France & cRCC & 131 & PFS & Yes & $72(4.2-184)$ & $\begin{array}{l}\text { High versus Low } \\
\text { (high }>=85 \% \text {, } \\
\text { moderate } 50 \% \text { - } \\
85 \% \text {, weak }<50 \% \text {, } \\
\text { and absence }=0 \%)\end{array}$ & Report & Surgery \\
\hline $\begin{array}{l}\text { Hongbin Liu } \\
{[14]}\end{array}$ & 2013 & China & ESCC & 80 & OS & No & $>60$ & $\begin{array}{c}\text { High }(\text { scores }>=3) \\
\text { versus Low } \\
(\text { Scores }<3)\end{array}$ & Extracted & Surgery \\
\hline Kai Wu [15] & 2010 & China & GBC & 200 & OS & Yes & 38(median) & 75th percentile & Report & Surgery \\
\hline $\begin{array}{l}\text { Tiecheng } \\
\text { Zhang [11] }\end{array}$ & 2012 & China & $\mathrm{GC}$ & 220 & OS & Yes & $>60$ & $\begin{array}{c}\text { Positive }(>4) \text { versus } \\
\text { negative }(<4)\end{array}$ & Report & Surgery \\
\hline D. Aydin [12] & 2015 & Turkey & $\mathrm{GC}$ & 156 & OS/DFS & Yes & $>60$ & $\begin{array}{c}\text { High }(\text { scores }>=4) \\
\text { versus Low } \\
(\text { Scores }<4)\end{array}$ & Report & Surgery \\
\hline $\begin{array}{l}\text { Shuangshuang } \\
\text { Ni [9] }\end{array}$ & 2013 & China & NSCLL & 124 & OS & Yes & $>60$ & $\begin{array}{c}\text { High }(\text { scores }>=4) \\
\text { versus Low } \\
(\text { Scores }<4)\end{array}$ & Report & Surgery \\
\hline Qin Xu [16] & 2014 & China & UCC & 110 & OS/PFS & Yes & $>72$ & $\begin{array}{l}(-) \text { indicated }<10 \\
\% \text { of cells stained } \\
\text { positively, }(+)=10- \\
25 \% \text { of cells, } \\
(++)=26-50 \% \text { of } \\
\text { cells, and }(+++) \geq 50 \\
\% \text { of cells showed } \\
\text { positive staining. }\end{array}$ & Report & Surgery \\
\hline $\begin{array}{l}\text { P. M. } \\
\text { McGowan [17] }\end{array}$ & 2008 & Ireland & $\mathrm{BC}$ & 153 & OS & Yes & 37(median) & $\begin{array}{l}75 \text { th versus }>75 \text { th } \\
\text { percentile }\end{array}$ & Report & Mixed \\
\hline Yong Tan [18] & 2015 & China & ECC & 78 & OS/PFS & Yes & 22.5 (median) & $\begin{array}{c}\text { High }(\text { scores }>=4) \\
\text { versus Low } \\
(\text { Scores }<4)\end{array}$ & Extracted & Surgery \\
\hline Bin Wu [19] & 2014 & China & Glioma & 60 & OS & No & NA & $\begin{array}{c}\text { High }(>45 \% \\
\text { positive cells) } \\
\text { versus Low }(<45 \% \\
\text { positive cells) }\end{array}$ & Extracted & Mixed \\
\hline $\begin{array}{l}\text { Yoshihiro } \\
\text { Tanaka [20] }\end{array}$ & 2005 & Japan & $\mathrm{OC}$ & 68 & PFS & No & 30 median & $\begin{array}{c}\text { Positive }(>4) \text { versus } \\
\text { negative }(<4)\end{array}$ & Extracted & Mixed \\
\hline $\begin{array}{l}\text { Zhangxuan } \\
\text { Shou [13] }\end{array}$ & 2012 & China & GC & 436 & OS & Yes & $>60$ & $\begin{array}{c}\text { High }(\text { scores }>=4) \\
\text { versus Low } \\
(\text { Scores }<4)\end{array}$ & Report & Mixed \\
\hline
\end{tabular}

cRCC: clear cell renal cell carcinoma, ESCC: esophageal squamous cell carcinoma, GBC: gallbladder carcinoma, GC: gastric cancer, NSCLL: non-small cell lung cancer, UCC: uterine cervical carcinoma, BC: breast cancer, HNSCC: squamous cell carcinoma of the head and neck, OC: ovarian cancer, PFS: progression-free survival, OS: overall survival, NA: not available. 
Table 2: Summary of original lymph node and distant metastasis data

\begin{tabular}{lccccc}
\hline Type & Study & \multicolumn{2}{c}{ Low expression } & \multicolumn{2}{c}{ High expression } \\
\cline { 3 - 5 } & & Events & Total & Events & Total \\
\hline LNM & Hongbin Liu (2013) & 6 & 27 & 29 & 53 \\
& Shuangshuang Ni (2013) & 15 & 59 & 38 & 65 \\
& Qin Xu (2014) & 2 & 32 & 36 & 78 \\
& Yong Tan (2015) & 8 & 37 & 27 & 41 \\
& Zhangxuan Shou (2012) & 135 & 280 & 135 & 156 \\
& D. Aydin (2015) & 45 & 77 & 64 & 79 \\
DM & & & & \\
& Tiecheng Zhang (2012) & 2 & 38 & 28 & 182 \\
& Zhangxuan Shou (2012) & 18 & 280 & 43 & 796 \\
\hline
\end{tabular}

LNM: lymph node metastasis, DM: distant metastasis.

Table 3: Associations between ADAM17 expression and prognosis and metastasis in cancer patients

\begin{tabular}{lcccccccc}
\hline Variables & Outcome & Studies & Patients & HR(95\%) & P-value & Model & \multicolumn{2}{c}{ Heterogenetity } \\
\cline { 3 - 8 } & & & & & & & $\mathbf{I}^{2}(\%)$ & $\boldsymbol{P}$-value \\
\hline All & OS & 10 & 1617 & $2.04(1.66,2.52)$ & $<0.001$ & Fixed & 14.7 & 0.308 \\
& PFS & 5 & 543 & $1.81(1.30,2.53)$ & $<0.001$ & Fixed & 33.9 & 0.195 \\
& LNM & 6 & 984 & $5.47(3.98,7.51)$ & $<0.001$ & Fixed & 10.1 & 0.351 \\
& DM & 3 & 812 & $3.50(1.79,6.87)$ & $<0.001$ & Random & 52.8 & 0.12 \\
Analysis type & & & & & & & & \\
Multivariate & OS & 8 & 1477 & $2.07(1.65,2.61)$ & $<0.001$ & Fixed & 32.8 & 0.166 \\
& PFS & 4 & 475 & $2.13(1.46,3.10)$ & $<0.001$ & Fixed & 0 & 0.415 \\
Univariate & OS & 2 & 140 & $1.86(1.08,3.21)$ & 0.026 & Fixed & 0 & 0.97 \\
& PFS & 1 & 68 & $1.01(0.49,2.08)$ & - & - & - & - \\
\hline
\end{tabular}

OS: overall survival, PFS: progression-free survival, LNM: lymph node metastasis, DM: distant metastasis.

node metastasis. Meta-analysis of the fixed effect model revealed that ADAM17 overexpression was more common in patients with lymph node metastasis than in those without lymph node metastasis $\left(I^{2}=10.1 \%\right.$; $P=0.351$, $\mathrm{OR}=5.47,95 \%$ CI $3.98-7.51, P<0.001$ ) (Figure 4$)$.

\section{ADAM17 expression is associated with distant metastasis}

Three articles examined ADAM17 overexpression in cancer tissues from patients with and without distant metastasis. Meta-analysis of the random effect model revealed that ADAM17 overexpression was more common in patients with distant metastasis than in those without distant metastasis $\left(\mathrm{I}^{2}=52.8 \% ; P=0.12, \mathrm{OR}=3.50,95 \% \mathrm{CI}\right.$ $1.79-6.87, P<0.001$ ) (Figure 5).

\section{Elevated ADAM17 expression is associated with poor prognosis}

Ten studies reported data on OS for eight different tumor types (Figure 2). Because no significant heterogeneity was identified $\left(\mathrm{I}^{2}=14.7 \%, P=0.308\right)$, the fixed-effects model was used to estimate pooled HRs 
and corresponding 95\% CIs for low and high ADAM17 expression groups. Compared with low ADAM17 expression group, OS times were shorter in the high ADAM17 expression group than in the low ADAM17 expression group $(\mathrm{HR}=2.04,95 \%$ CI 1.66-2.52, $P<0.001)$. Five studies reported data on progressionfree survival (PFS) for five different tumor types (Figure 3). Because no significant heterogeneity was
Study

ID
$\%$

$\operatorname{HR}(95 \% \mathrm{Cl})$

Weight

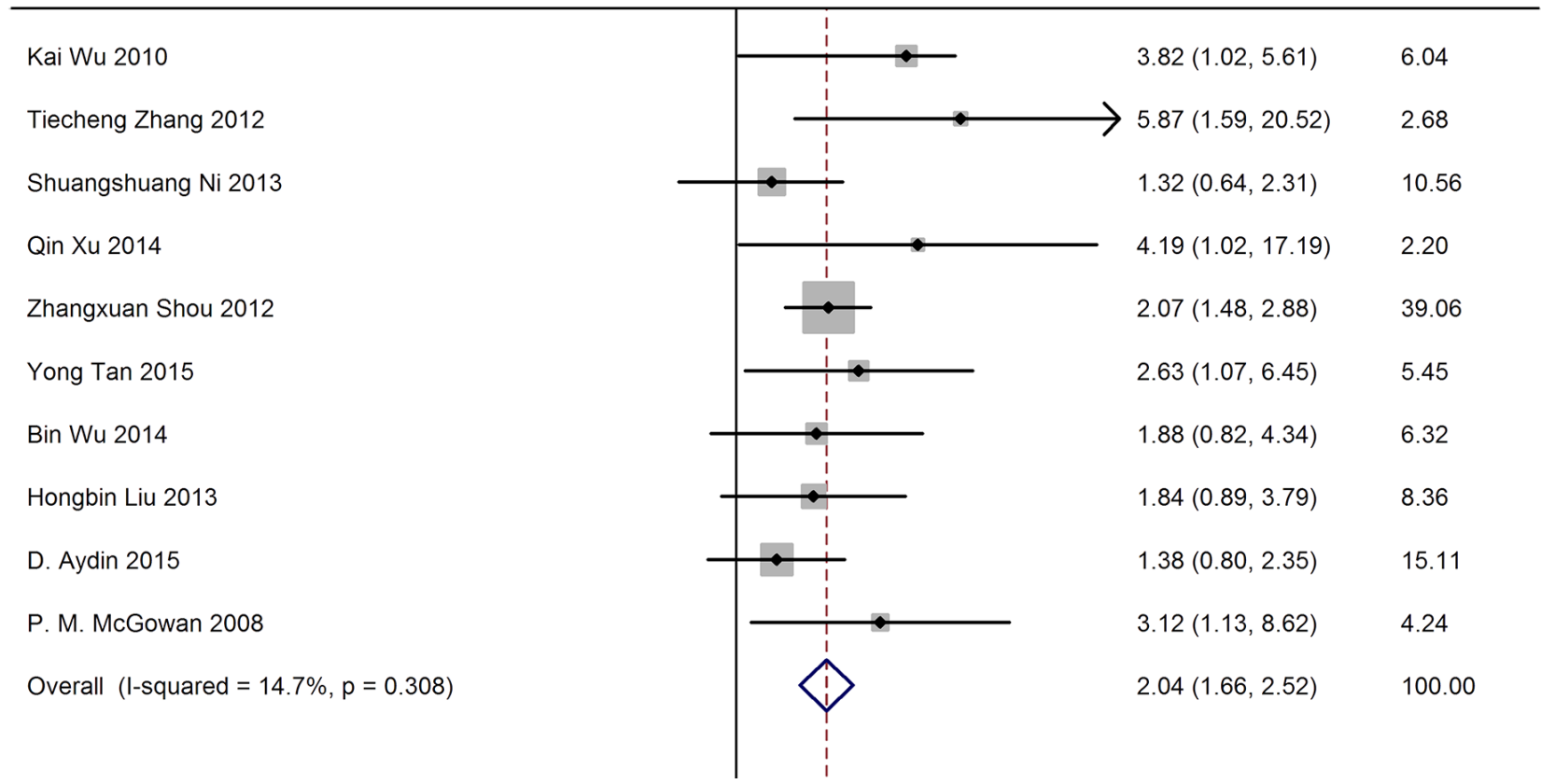

Figure 2: Forest plot of the association between ADAM17 expression and overall survival.

$$
\text { Study }
$$

ID

Qin Xu 2014
Yong Tan 2015
Guorong Li 2014
D. Aydin 2015
Yoshihiro Tanaka 2005
Overall (l-squared $=33.9 \%, p=0.195$ )

$\operatorname{HR}(95 \% \mathrm{Cl})$

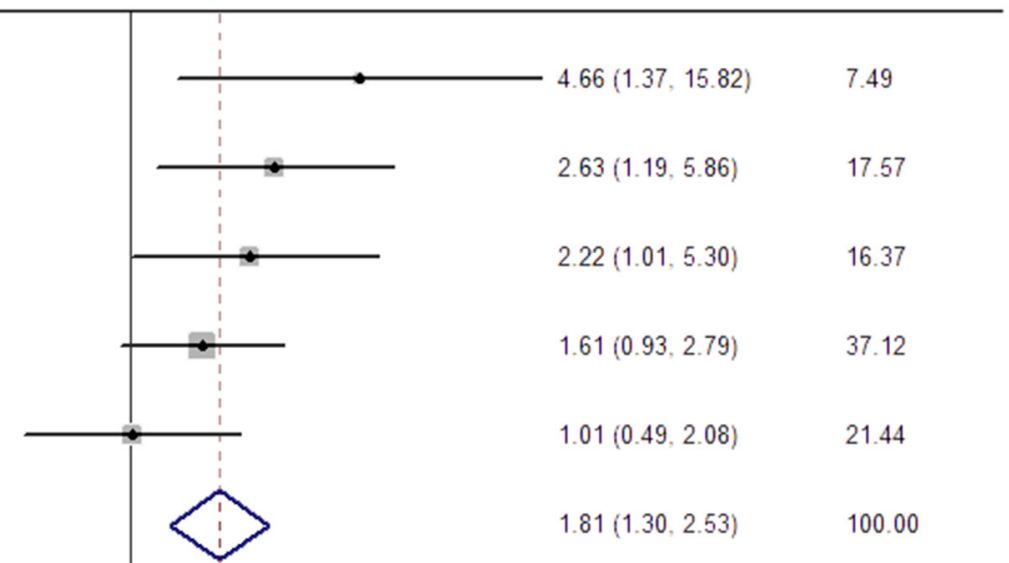

Figure 3: Forest plot of the association between ADAM17 expression and progression-free survival. 
identified $\left(\mathrm{I}^{2}=33.9 \%, P=0.195\right)$, the fixed-effects model was used to pool PFS data. The pooled HR of $1.81(95 \%$ $\mathrm{CI}=130-2.53, P<0.001)$ indicated that ADAM17 overexpression was associated with poorer OS and PFS. Subgroup analysis was also performed to explore the influence of analysis type on survival findings. As shown in Table 3, the results of subgroup analysis confirmed the above findings.

\section{Publication bias and sensitivity analysis}

Publication bias was evaluated for LNM, DM, OS, and PFS using funnel plots. The funnel plots were almost symmetrical (Figure 6). Begg's test indicated that there was no publication bias in our meta-analysis. Analyses were then repeated after each study was removed one at a time to determine whether any single study altered the overall results (Figure 7). The results indicated that no single study had a significant effect on the final results, suggesting that the findings are robust.

\section{DISCUSSION}

The adisintegrin and metalloprotease (ADAM) family proteins are $\mathrm{Zn}^{2+}$-dependent proteases that cleave

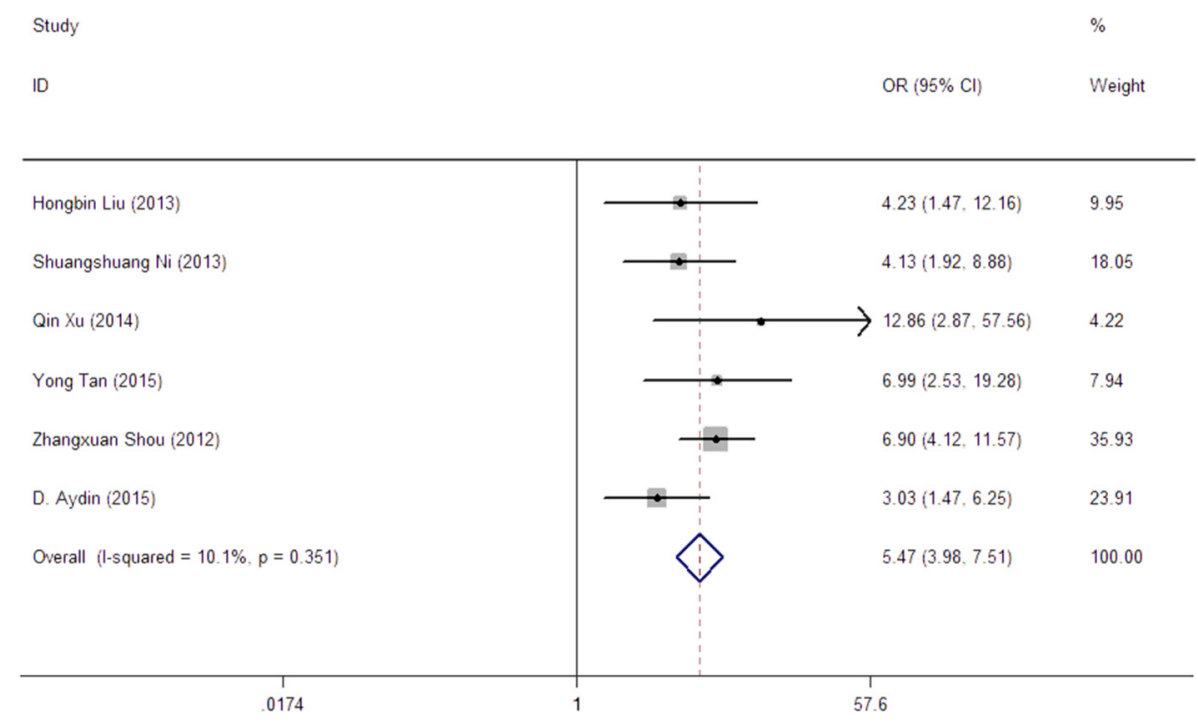

Figure 4: Forest plot of the association between ADAM17 expression and lymph node metastasis.

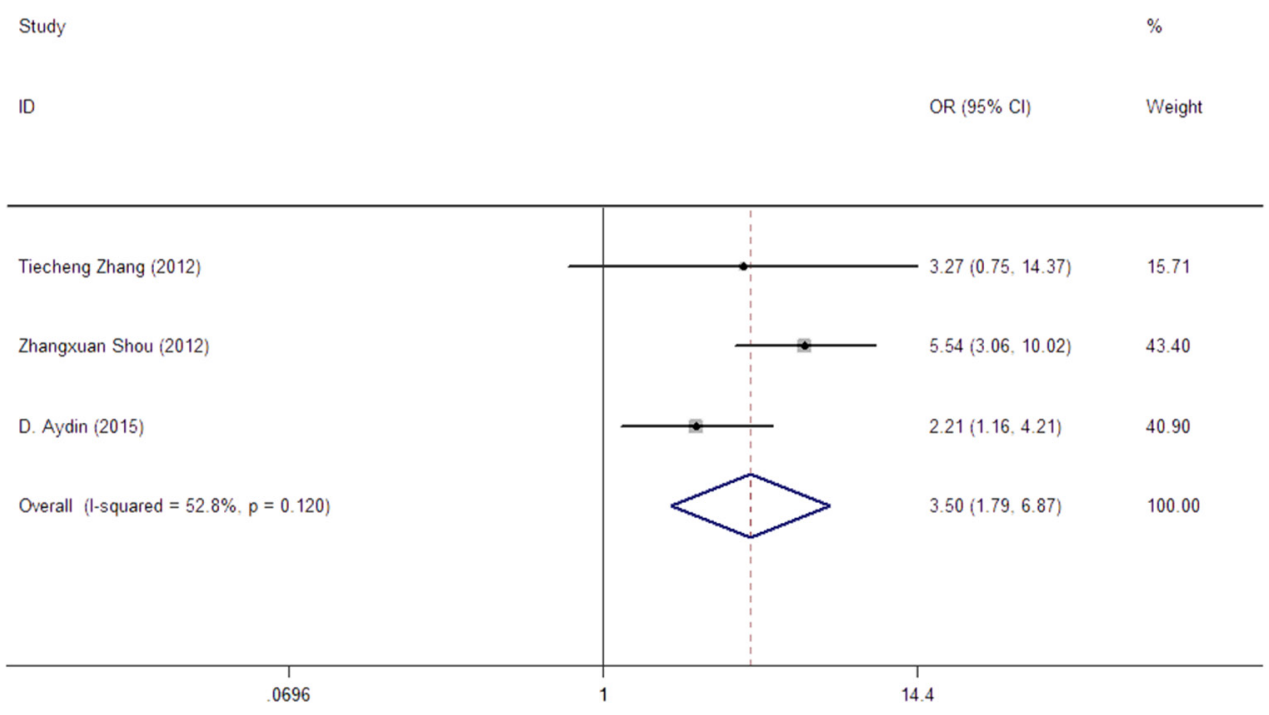

Figure 5: Forest plot of the association between ADAM17 expression and distant metastasis. 
membrane-bound proteins and/or degrade the extracellular matrix [21]. ADAMs participate in cellular adhesion and in proteolytic cleavage of various cell surface molecules. They are therefore important mediators of cell signaling events which regulate cellular fate, proliferation, and growth [22, 23]. Recent studies have demonstrated that ADAMs are involved in various diseases, such as inflammatory bowel disease [24], systemic lupus erythematosus [25], neurodegenerative diseases [26]. Meanwhile, abnormal expression of ADAMs has been detected in tumor tissues and is a crucial contributor to oncogenic processes and aggressive progression in malignant tumors [27]. These findings indicate that the functions of ADAMs should be studied further.

ADAM17 was simultaneously identifiedin 1997 by two research groups as the enzyme responsible for cleavage of the transmembrane protein Tumor Necrosis Factor (TNF)- $\alpha$; it was therefore originally named TNF$\alpha$-converting enzyme (TACE) [28, 29]. It is composed of 824 amino acids, and its gene is located on chromosome

\section{A}

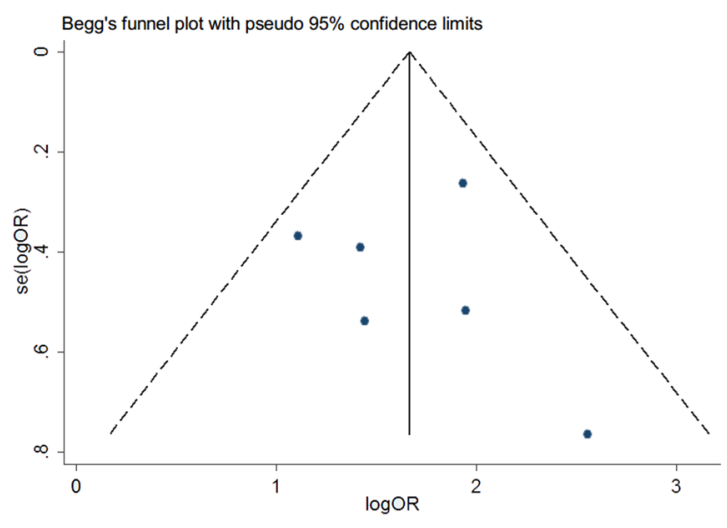

C

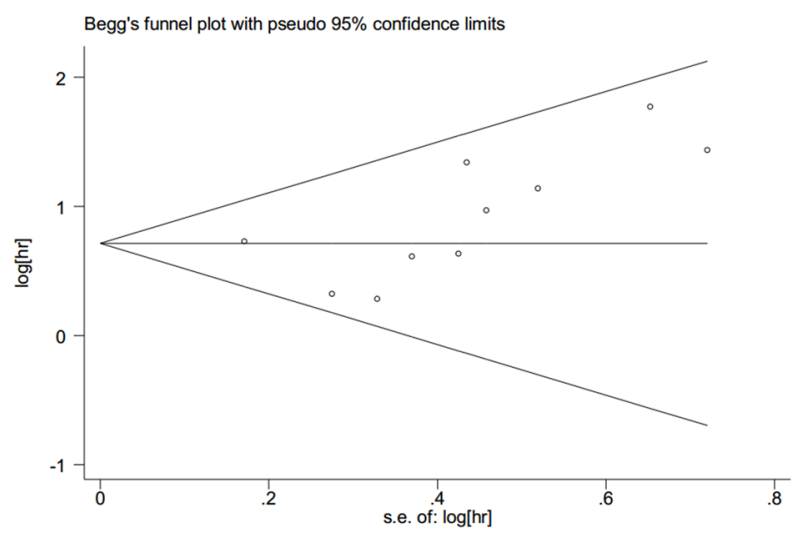

$2 q 25$ [8]. ADAM17 is expressed in the kidneys, skeletal muscle, brain, and other normal tissues, and its expression is up-regulated in various types of tumor tissue [28, 30]. Downregulation of ADAM17 expression can suppress proliferation and migration in tumor cell lines, suggesting that ADAM17 might be a potential antitumor therapeutic target [31]. In clear cell renal cell carcinoma, Li et al. [10] found that higher ADAM17 expression was associated with more advanced clinical characteristics and poorer prognosis. In 2016, Shenetal. reported that a marked increase in ADAM17 expression on the cell surface was associated with increased tumorigenesis, invasiveness, and drug resistance in breast cancer [30]. Lv et al. [32] demonstrated that downregulation of ADAM17 using an RNA silencing approach suppressed cell proliferation and invasion in vitro and tumor growth in non-small cell lung carcinoma. Accumulating evidence demonstrates that ADAM17 modulates many signaling pathways that control physiological and pathophysiological processes such

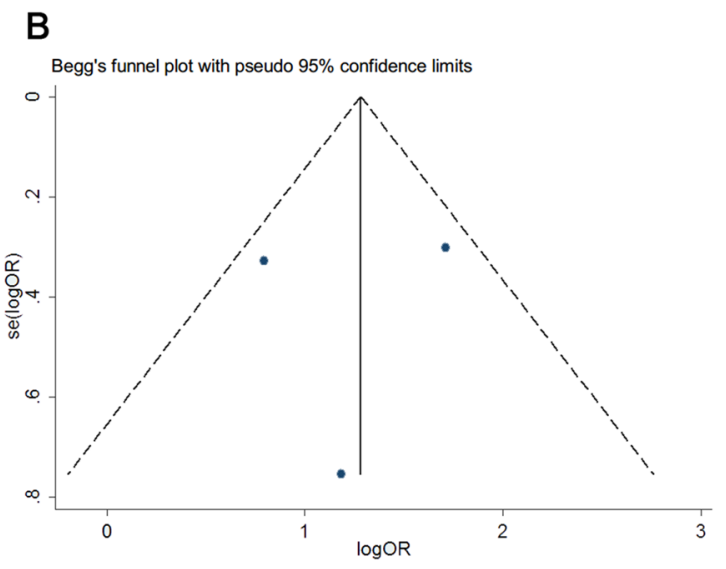

D

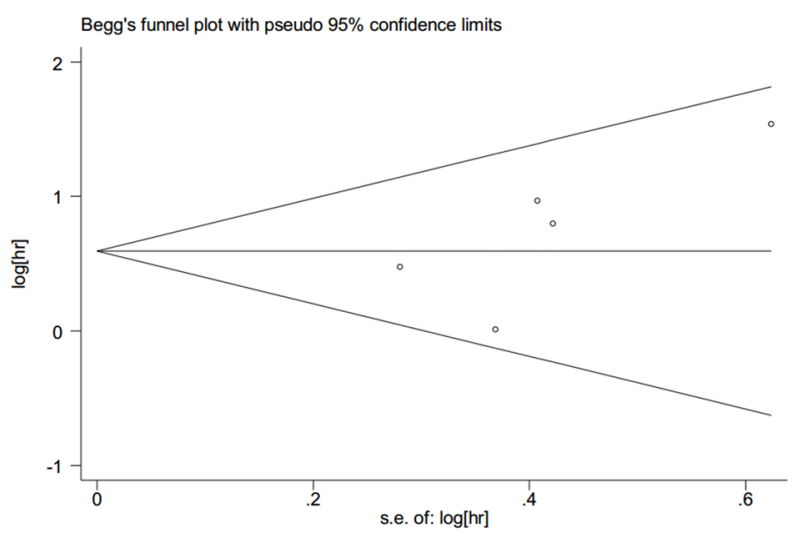

Figure 6: Begg's test for publication bias. (A) Lymph node metastasis. (B) Distant metastasis. (C) Overall survival. (D) Progressionfree survival. 
as development, regeneration, immunity, inflammation, and tumorigenesis [33]. ADAM17 has such wideranging effects mainly because it interacts with many different substrates. So far, more than 70 substrates have been identified, including epidermal growth factor receptor (EGFR/ErB1) ligands, amphiregulin (AREG), epiregulin, heparin-binding epidermal growth factor (HB-EGF), c-kit, CD40, interleukin-6 receptor, vascular cell adhesion molecule-1, and Notch [34, 35]. However, the exact molecular mechanisms underlying associations between ADAM17 expression and cancer progression need to be further elucidated.

To our knowledge, this is the first metaanalysis to examine correlations between ADAM17 expression and clinical outcomes in cancer patients. The pooled results strongly suggest that elevated ADAM17 expression decreases OS and PFS in cancer patients, indicating that ADAM17 may be a promising biomarker for predicting prognosis in cancer patients. In addition, we found that higher ADAM17 expressionwas associated with increased LNM and DM, indicating that increased ADAM17 expression may be related to

A

Meta-analysis estimates, given named study is omitted
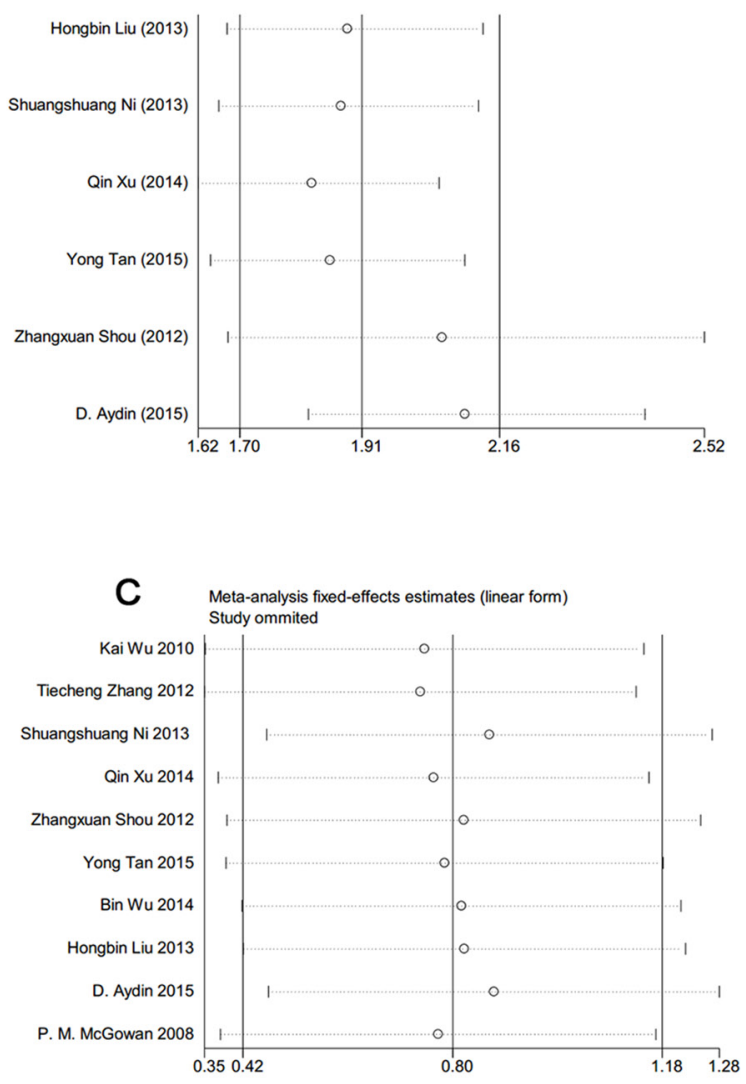

cancer progression. Furthermore, a sensitivity analysis revealed that no single study had a significant effect on the observed effect size (pooled HR), indicating that the findings were robust.

Several limitations to the present study should be considered when interpreting the results. First, the cut-off values used to define high ADAM17 expression differed among the studies examined. Second, all included studies were retrospective analyses, and some had small sample sizes. Third, most of the included studies reported significant findings, and it is likely that any relevant studies reporting negative results have not been published. Therefore, multi-center, prospective studies with larger sample sizes and uniform criteria for categorizing ADAM17 expression are needed to confirm the findings of this study.

In conclusion, our systematic review and metaanalysis indicates that elevated ADAM17 expression is significantly associated with increases in LNM and $\mathrm{DM}$ and poorer survival outcomes in cancer patients. Moreover, ADAM17 might serve as a novel prognostic biomarker and a promising therapeutic target.
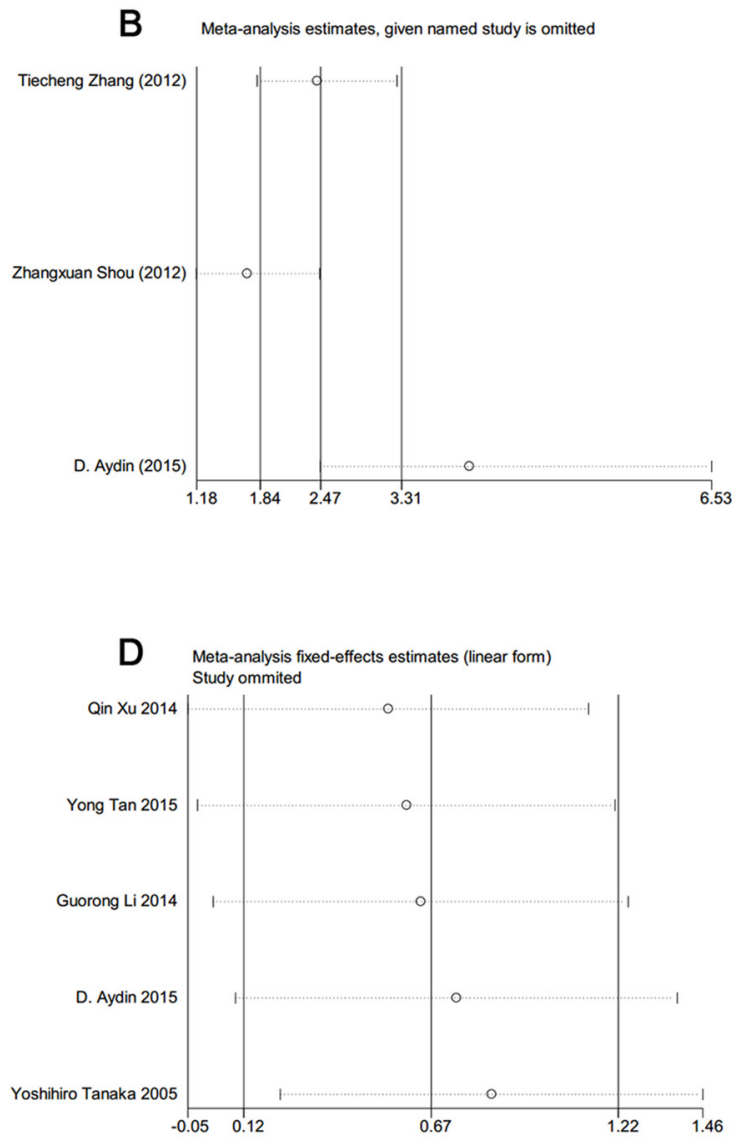

Figure 7: Sensitivity analyses of the meta-analysis results. (A) Lymph node metastasis. (B) Distant metastasis. (C) Overall survival. (D) Progression-free survival. 


\section{MATERIALS AND METHODS}

\section{Search strategy and selection of studies}

This meta-analysis was conducted according to the Preferred Reporting Items for Systematic Reviews and Meta-Analyses (PRISMA) statement [36]. We searched the PubMed, Embase, Cochrane, and Chinese National Knowledge Infrastructure databases for studies published through June 2017. Both MHSH (medical subject heading terms) and free-words were used in the search strategy to increase its sensitivity. The following search terms used were used: "cancer or tumor or neoplasm" and "ADAM17 or Disintegrin and Metalloproteinase Domain Containing Protein 17 or Tumor Necrosis Factor Alpha Convertase or Tumor Necrosis Factor alpha Converting Enzyme or TNFalpha Converting Enzyme" and "survival or prognostic or prognosis or recurrence or clinical outcome". There were no language restrictions. We also screened the references of all papersidentified using this search strategy to identify additional potential eligible studies.

\section{Inclusion and exclusion criteria}

Studies were eligible for inclusion in this metaanalysis if they met the following criteria: 1) evaluated associations between ADAM17 protein expression and prognosis incancer patients; 2) cancer diagnosis was pathologically confirmed; 3) cohort design; 4) studies supplied sufficient information for calculating hazard ratio (HR) and 95\% confidence interval (CI). If the articles only provided survival curves, relevant data were extracted from the survival curves usingEngauge Digitizer 4.1 software, and $\log H \mathrm{R}$ and selogHRwere calculated according to Parmar et al. [37] and Tierney et al. [38]. The exclusion criteria were as follows: 1) duplicated studies using the same population or overlapping patient database; 2) reviews, comments, letters, conference abstracts, and case reports; 3 ) insufficient data for calculating HR and 95\% CI; 4) evaluated associations between ADAM17 mRNA expression and clinical characteristics; 5) evaluated associations between ADAM17activity and clinical characteristics.

\section{Quality assessment}

The quality of the included studies was assessed according to the Newcastle-Ottawa Scale (NOS) [39]. This included an assessment of subject selection, comparability of groups, and clinical outcome. Quality scores ranged from 0 (lowest) to 9 (highest); studies with a NOS score $\geq 7$ were considered high-quality.

\section{Data extraction}

All data were extracted from the studies by two independent investigators. Any disagreements were resolved by a third reviewer. Study characteristics included first author's name, year of publication, country, case number, time of follow-up, type of tumor, cut-off value, treatment, survival analysis methods (univariate, multivariate); outcome measures included HRs and 95\% CIs for OS or PFS.

\section{Statistical analysis}

Statistical analyses were conducted using STATA version 12.0 (Stata Corporation, College Station, TX, USA). HRs and 95\% CI were used to evaluate the relationship between ADAM17 and cancer prognosis (overall survival and progression-free survival). Odds ratios (ORs) and 95\% CIs were used to assess the relationship between ADAM17 and clinical characteristics, which included distant metastasis (DM) and lymph node metastasis (LNM). Homogeneity of HRs and ORs across the studies was evaluated using the $\mathrm{Q}$ and $\mathrm{I}^{2}$ statistics; statistically significant heterogeneity was defined by a $p$-value $<0.10$ for the Q-test or an $\mathrm{I}^{2}$ value $>50 \%$. In the absence of significant heterogeneity, we pooled results using a fixed effect model; otherwise, a random effect model was used. Publication bias was evaluated by examining asymmetry of an inverted funnel plot. We also performed Begg's test to obtain quantitative evidence regarding publication bias. Sensitivity analyses were carried out to evaluate the stability of our results when individual studies were removed one at a time. All statistical tests were two-sided, and a $P<0.05$ was considered statistically significant.

\section{ACKNOWLEDGMENTS}

We are indebted to the donors, whose names are not included in the author list but who participated in this program.

\section{CONFLICTS OF INTEREST}

All authors declare that there are no conflicts of interest.

\section{REFERENCES}

1. Cui X, Jing $\mathrm{X}$, Long $\mathrm{C}$, Tian J, Zhu J. Long noncoding RNA MEG3, a potential novel biomarker to predict the clinical outcome of cancer patients: a meta-analysis. Oncotarget. 2017; 8:19049-56. https://doi.org/10.18632/ oncotarget.14987.

2. Vickers AJ, Thompson IM, Klein E, Carroll PR, Scardino PT. A commentary on PSA velocity and doubling time for clinical decisions in prostate cancer. Urology. 2014; 83:5926. https://doi.org/10.1016/j.urology.2013.09.075.

3. Zhang G, Ha SA, Kim HK, Yoo J, Kim S, Lee YS, Hur SY, Kim YW, Kim TE, Park YG, Wang J, Yang Y, Xu Z, 
et al. Combined analysis of AFP and HCCR-1 as an useful serological marker for small hepatocellular carcinoma: a prospective cohort study. Dis Markers. 2012; 32:265-71. https://doi.org/10.3233/DMA-2011-0878.

4. Li N, Tian GW, Wang Y, Zhang H, Wang ZH, Li G. Prognostic role of the pretreatment C-reactive protein/ albumin ratio in solid cancers: a meta-analysis. Sci Rep. 2017; 7:41298. https://doi.org/10.1038/srep41298.

5. Giebeler N, Zigrino P. A disintegrin and metalloprotease (ADAM): historical overview of their functions. Toxins (Basel). 2016; 8:122. https://doi.org/10.3390/toxins8040122.

6. Misra S, Chaturvedi A, Misra NC, Sharma ID. Carcinoma of the gallbladder. Lancet Oncol. 2003; 4:167-76.

7. Szalad A, Katakowski M, Zheng X, Jiang F, Chopp M. Transcription factor Sp1 induces ADAM17 and contributes to tumor cell invasiveness under hypoxia. J Exp Clin Cancer Res. 2009; 28:129. https://doi. org/10.1186/1756-9966-28-129.

8. Gooz M. ADAM-17: the enzyme that does it all. Crit Rev Biochem Mol Biol. 2010; 45:146-69. https://doi. org/10.3109/10409231003628015.

9. Ni SS, Zhang J, Zhao WL, Dong XC, Wang JL. ADAM17 is overexpressed in non-small cell lung cancer and its expression correlates with poor patient survival. Tumour Biol. 2013; 34:1813-8. https://doi.org/10.1007/ s13277-013-0721-3.

10. Li G, Forest F, Feng G, Gentil-Perret A, Peoc'h M, Cottier M, Mottet N. A novel marker ADAM17 for clear cell renal cell carcinomas: implication for patients' prognosis. Urol Oncol. 2014; 32:1272-6. https://doi.org/10.1016/j. urolonc.2014.05.011.

11. Zhang TC, Zhu WG, Huang MD, Fan RH, Chen XF. Prognostic value of ADAM17 in human gastric cancer. Med Oncol. 2012; 29:2684-90. https://doi.org/10.1007/ s12032-011-0125-4.

12. Aydin D, Bilici A, Yavuzer D, Kefeli U, Tan A, Ercelep O, Mert A, Yuksel S, Ozcelik M, Isik D, Surmeli H, Odabasi $\mathrm{H}$, Aliustaoglu M. Prognostic significance of ADAM17 expression in patients with gastric cancer who underwent curative gastrectomy. Clin Transl Oncol. 2015; 17:604-11. https://doi.org/10.1007/s12094-015-1283-1.

13. Shou ZX, Jin X, Zhao ZS. Upregulated expression of ADAM17 is a prognostic marker for patients with gastric cancer. Ann Surg. 2012; 256:1014-22. https://doi. org/10.1097/SLA.0b013e3182592f56.

14. Liu HB, Yang QC, Shen Y, Zhu Y, Zhang XJ, Chen H. A disintegrin and metalloproteinase $17 \mathrm{mRNA}$ and protein expression in esophageal squamous cell carcinoma, as well as its clinicopathological factors and prognosis. Mol Med Rep. 2015; 11:961-7. https://doi.org/10.3892/mmr.2014.2802.

15. Wu K, Liao M, Liu B, Deng Z. ADAM-17 over-expression in gallbladder carcinoma correlates with poor prognosis of patients. Med Oncol. 2011; 28:475-80. https://doi. org/10.1007/s12032-010-9481-8.
16. Xu Q, Ying M, Chen G, Lin A, Xie Y, Ohara N, Zhou D. ADAM17 is associated with EMMPRIN and predicts poor prognosis in patients with uterine cervical carcinoma. Tumour Biol. 2014; 35:7575-86. https://doi.org/10.1007/ s13277-014-1990-1.

17. McGowan PM, McKiernan E, Bolster F, Ryan BM, Hill AD, McDermott EW, Evoy D, O'Higgins N, Crown J, Duffy MJ. ADAM-17 predicts adverse outcome in patients with breast cancer. Ann Oncol. 2008; 19:1075-81. https:// doi.org/10.1093/annonc/mdm609.

18. Yong $\mathrm{T}$, Baoan $\mathrm{Q}$, Yuhong $\mathrm{M}$, Jianyong $\mathrm{Z}$, Nianxin $\mathrm{X}$, Yingxiang Y, Peng L, Yang Z. The prognostic value of overexpression of ADAM17 in patients with extrahepatic cholangiocarcinoma after resection. Chin J Hepatobiliary Surg. 2015; 21:674-7.

19. Wu B, Sha L, Wang Y, Xu W, Yu Y, Feng F, Sun C, Xia L. Diagnostic and prognostic value of a disintegrin and metalloproteinase-17 in patients with gliomas. Oncol Lett. 2014; 8:2616-20. https://doi.org/10.3892/ ol.2014.2582.

20. Tanaka Y, Miyamoto S, Suzuki SO, Oki E, Yagi H, Sonoda K, Yamazaki A, Mizushima H, Maehara Y, Mekada E, Nakano H. Clinical significance of heparin-binding epidermal growth factor-like growth factor and a disintegrin and metalloprotease 17 expression in human ovarian cancer. Clin Cancer Res. 2005; 11:4783-92. https://doi. org/10.1158/1078-0432.CCR-04-1426.

21. Lisi S, D'Amore M, Sisto M. ADAM17 at the interface between inflammation and autoimmunity. Immunol Lett. 2014; 162:159-69. https://doi.org/10.1016/j. imlet.2014.08.008.

22. Edwards DR, Handsley MM, Pennington CJ. The ADAM metalloproteinases. Mol Aspects Med. 2008; 29:258-89. https://doi.org/10.1016/j.mam.2008.08.001.

23. Blobel CP. ADAMs: key components in EGFR signalling and development. Nat Rev Mol Cell Biol. 2005; 6:32-43. https://doi.org/10.1038/nrm1548.

24. Brandl K, Tomisato W, Beutler B. Inflammatory bowel disease and ADAM17 deletion. N Engl J Med. 2012; 366:190; author reply. https://doi.org/10.1056/ NEJMc1113859\#SA1.

25. Zhu H, Sun X, Zhu L, Hu F, Shi L, Li Z, Su Y. The expression and clinical significance of different forms of Mer receptor tyrosine kinase in systemic lupus erythematosus. J Immunol Res. 2014; 2014:431896. https:// doi.org/10.1155/2014/431896.

26. Wang M, Li Y, Lu Y, Zuo X, Wang F, Zhang Z, Jia J. The relationship between ADAM17 promoter polymorphisms and sporadic Alzheimer's disease in a Northern Chinese Han population. J Clin Neurosci. 2010; 17:1276-9. https:// doi.org/10.1016/j.jocn.2010.01.008.

27. Mochizuki S, Okada Y. ADAMs in cancer cell proliferation and progression. Cancer Sci. 2007; 98:621-8. https://doi. org/10.1111/j.1349-7006.2007.00434.x. 
28. Black RA, Rauch CT, Kozlosky CJ, Peschon JJ, Slack JL, Wolfson MF, Castner BJ, Stocking KL, Reddy P, Srinivasan S, Nelson N, Boiani N, Schooley KA, et al. A metalloproteinase disintegrin that releases tumour-necrosis factor-alpha from cells. Nature. 1997; 385:729-33. https:// doi.org/10.1038/385729a0.

29. Moss ML, Jin SL, Milla ME, Bickett DM, Burkhart W, Carter HL, Chen WJ, Clay WC, Didsbury JR, Hassler D, Hoffman CR, Kost TA, Lambert MH, et al. Cloning of a disintegrin metalloproteinase that processes precursor tumour-necrosis factor-alpha. Nature. 1997; 385:733-6. https://doi.org/10.1038/385733a0.

30. Shen H, Li L, Zhou S, Yu D, Yang S, Chen X, Wang D, Zhong S, Zhao J, Tang J. The role of ADAM17 in tumorigenesis and progression of breast cancer. Tumour Biol. 2016. https://doi.org/10.1007/s13277-016-5418-y.

31. Guo Z, Jin X, Jia H. Inhibition of ADAM-17 more effectively down-regulates the Notch pathway than that of gamma-secretase in renal carcinoma. J Exp Clin Cancer Res. 2013; 32:26. https://doi.org/10.1186/1756-9966-32-26.

32. Lv X, Li Y, Qian M, Ma C, Jing H, Wen Z, Qian D. ADAM17 silencing suppresses the migration and invasion of non-small cell lung cancer. Mol Med Rep. 2014; 9:193540. https://doi.org/10.3892/mmr.2014.2029.
33. Grotzinger J, Lorenzen I, Dusterhoft S. Molecular insights into the multilayered regulation of ADAM17: the role of the extracellular region. Biochim Biophys Acta. 2017; 1864:2088-95. https://doi.org/10.1016/j.bbamcr.2017.05.024.

34. Arribas J, Esselens C. ADAM17 as a therapeutic target in multiple diseases. Curr Pharm Des. 2009; 15:2319-35.

35. Horiuchi K. A brief history of tumor necrosis factor alpha-converting enzyme: an overview of ectodomain shedding. Keio J Med. 2013; 62:29-36.

36. Moher D, Liberati A, Tetzlaff J, Altman DG; PRISMA Group. Preferred reporting items for systematic reviews and meta-analyses: the PRISMA statement. Int J Surg. 2010; 8:336-41. https://doi.org/10.1016/j.ijsu.2010.02.007.

37. Parmar MK, Torri V, Stewart L. Extracting summary statistics to perform meta-analyses of the published literature for survival endpoints. Stat Med. 1998; 17:2815-34.

38. Tierney JF, Stewart LA, Ghersi D, Burdett S, Sydes MR. Practical methods for incorporating summary time-to-event data into meta-analysis. Trials. 2007; 8:16. https://doi. org/10.1186/1745-6215-8-16.

39. Moher D, Liberati A, Tetzlaff J, Altman DG; PRISMA Group. Preferred reporting items for systematic reviews and meta-analyses: the PRISMA statement. Int J Surg. 2010; 8:336-41. https://doi.org/10.1016/j.ijsu.2010.02.007. 